\title{
Reversible Complete Atrioventriculer Block in Patient with Mild Hyperkalemia
}

\begin{abstract}
Complete atrioventricular (AV) block or third degree AV block is a type of bradyarrhythmia that can be diagnosed as mortality if it is not noticed and treated. There are several causes of complete AV block and one of them is severe hyperkalemia. A 84 year-old woman known to type II diabetes mellitus, applied to emergency department with nausea, vomiting, fatigue, conscious semi-closed. Hypotension and complete AV block were detected. Lab findings showed metabolic asidosis and mild hyperkalemia (K:6,1 mmol/L). Fluid replacement, noradrenalin infusion, $\beta_{2}$ agonist and insuline infusion administered and her cardiac rythym returned sinus rythme without pacemaker or hemodialysis. Generally, hyperkalemia related complete AV block occures in severe hyperkalemia $(\mathrm{K}>7 \mathrm{mmol} / \mathrm{L})$ and a temporary pacemaker and/or hemodialysis are required for treatment. In this case report, serum potassium level was lower than $7 \mathrm{mmol} / \mathrm{L}$ but complete AV block occured and she was treated successfully without the temporaray pacemaker or hemodialysis.
\end{abstract}

Keywords: Complete atrioventriculer block; Mild hyperkalemia; Temporaray pacemaker; Intensive care unit

Case Report
Volume 11 Issue 1 - 2018
Behiye Deniz Kosovali ${ }^{1 *}$ and Huseyin Yild iz ${ }^{2}$
${ }^{1}$ Department of Intensive Care Unit, Malatya Education and
Reseacrh Hospital, Turkey
${ }^{2}$ Department of Internal Medicine, Malatya Education and
Reseacrh Hospital, Turkey
*Corresponding author: Behiye Deniz Kosovali,
Department of Intensive Care Unit, Malatya Education and
Reseacrh Hospital, 44330 Malatya, Turkey, Tel: +90 422 444
56 34; Fax: +90 422 232 53 43;
Email: kosovalideniz@yahoo.com
Received: November 15, 2017 | Published: January 09,
2018

\section{Introduction}

Complete atrioventriculer (AV) block or third degree AV block is a type of bradtarrhythmia that can be diagnosed as mortality if it is not noticed and treated. Complete AV block results from various pathologic states. The causes of AV block are as drugs, ischemic or infarctive causes, degenerative diseases, metabolic causes, infectious cause, rheumatic diseases, infiltrative processes, neuromuscular disorders, toxins and congenital causes. Common metabolic causes of AV block are as hypoxsemia, hyperkalemia, hypotiroidism.

Potassium $(\mathrm{K})$ is an extracellular ion with an important role in the electrophysiologic regulation of myocardial function. Different concentrations of high intracellular and low extracellular potassium ions, the opposite of which is true for sodium ion, are maintained by sodium potassium adenosine triphosphatase (Na$\mathrm{K}$ ATPase) pumps, giving rise to a resting membrane potential of $-90 \mathrm{mV}$ across the myocytes membrane. As a result, any change in extracellular potassium concentration may have a significant effect on myocyte electrophysiologic gain [1]. Serum potassium level greter than $5,5 \mathrm{mmol} / \mathrm{L}$ is hyperkalemia and severe hyperkalemia is defined as potassium level $>7 \mathrm{mmol} / \mathrm{L}$. Serum potassium $>7 \mathrm{mmol} / \mathrm{L}$ causes conduction abnormality such as prolonged QRS interval, AV nodal block, sinus bradycardia and or sine wave pattern [2,3]. Moreover, hyperkalemia is known to cause potentially lethal dysrhythmias including ventricular tachycardia, ventricular fibrillation, idioventricular rhythms, and asystole [3]. Complete AV block generally occurs with severe hyperkalemia. We present a case who was treated with mild hyperkalemia releated complete AV block without the temporary pacemaker.

\section{Case Presentation}

A 84 year-old woman known to type II diabetes mellitus (DM) and had irreguler insuline use. She applied to emergency department with nausea, vomiting, fatigue, conscious semi-closed and general condition disorder. On arrival to the intensive care unite (ICU), she was lethargic and dry mucous membranes. Her initial vital signs showed a normal temperature, pulse 35 beats/ minute, respiratory rate 20 breaths/minute, pulse oximetry $85 \%$ (5-6 L/minute mask oxygen), and blood pressure 90/40 $\mathrm{mmHg}$, mean arterial pressure (MAP) $50 \mathrm{mmHg}$. Examinations of the head, neck, chest, and abdomen were normal, showed no meningeal signs and Glaskow Coma Score (GKS) 10. Only bradyarrhythmia was defined, no additional sound or murmur heard on cardiovascular auscultation. Her glucose level, determined by a finger stick, was $305 \mathrm{mg} / \mathrm{dL}$ and arterial blood gas (ABG) analysis showed pH:7,18 partial oxygen pressure $\left(\mathrm{PaO}_{2}\right) 58$, partial carbondioxide pressure $\left(\mathrm{PaCO}_{2}\right) 45 \mathrm{mmHg}$, bicarbonate $\left(\mathrm{HCO}_{3}\right) 15 \mathrm{mmol} / \mathrm{L}$, lactate 3,6 $\mathrm{mmol} / \mathrm{L}$, base exess (BE) -10, saturation $\left(\mathrm{SaO}_{2}\right) 88 \%$. The patient was given supplemental oxygen, IV fluids replacement, and placed on a cardiac monitor. An immediate electrocardiogram (ECG) was done which obtained bradycardia with complete AV block at rate of 53 beat/min (Figure 1). Despite administration of approximately one liter normal saline the patient remained hypotensive, with a blood pressure of 85/55 $\mathrm{mmHg}$ and noradrenalin infusion $(0,5$ $\mu \mathrm{g} / \mathrm{kg} / \mathrm{dk}$ ) was added. On her blood sample results included leukocyte (WBC):7190/mm3, hematocrit (Htc):34\%, platelate (Plt):197000/mm3, glucose:272 $\mathrm{mg} / \mathrm{dL}$, urea:59 mg/dL, creatinine:1,11 mg/dL, sodium $(\mathrm{Na}): 129 \mathrm{mmol} / \mathrm{L}$, potassium (K):6,1 mmol/L, chlorine (Cl):100 mmol/L, troponin $\mathrm{I}<0,1 \mathrm{ng} / \mathrm{mL}$ (0-0,3 ng/mL normal range), $C$ reactive proteine (CRP):0,48 mg/ 
$\mathrm{dL}(0-0,5 \mathrm{mg} / \mathrm{dL}$ normal range). Immediately $10 \mathrm{~mL} 10 \%$ calcium gluconate was administed intravenously (IV) over 5 minutes, inhaler $\beta 2$ agoniste agent (salbutamol) and dextrose 5\% mixed with 10 IU insuline IV were started for treatment of hyperkalemia. Transthoracic echocardiography (ECHO) showed ejection fraction $50 \%$, bradycardia and no abnormal function. Consultant of cardiology was planned to applied the temporary pacemaker. The patient was prepared for procedure, approximately two hours later, her MAP was greater than $70 \mathrm{mmH}$, GCS improved 15 and controle $\mathrm{ABG}$ analysis showed $\mathrm{pH}: 7,26 \mathrm{PaCO}_{2}: 31 \mathrm{mmHg}$ $\mathrm{PaO}_{2}: 105 \mathrm{mmHg} \mathrm{HCO}_{3}: 17 \mathrm{mmol} / \mathrm{L}$, lactate:1,8 mmol7L, BE:-8 $\mathrm{SaO}_{2}: 97 \%, \mathrm{~K}: 5,5 \mathrm{mmol} / \mathrm{L}, \mathrm{Na}: 130 \mathrm{mmol} / \mathrm{L}$. At the same time on cardiac monitor we identified the patient's cardiac rhythm returned sinus rhythm and ECG showed sinus rhythm, too (Figure 2). The temporary pacemaker procedure was waived. The patient's clinical symptoms disappered and laboratoy findings recovered within 24 hours. Last lab results were urea: $46 \mathrm{mg} /$ $\mathrm{dl}$, creatinine:0,86 mg/dL, Na:136 mmol/L, K:4,2 mmol/l, Cl:105 $\mathrm{mmol} / \mathrm{L}, \mathrm{pH}: 7,35, \mathrm{HCO}_{3}: 21 \mathrm{mmol} / \mathrm{L}, \mathrm{PaO}_{2}: 75 \mathrm{mmHg}, \mathrm{PaCO}_{2}: 41$ $\mathrm{mmHg}, \mathrm{SaO}_{2}: 96 \%$. She was discharged from ICU to general ward.

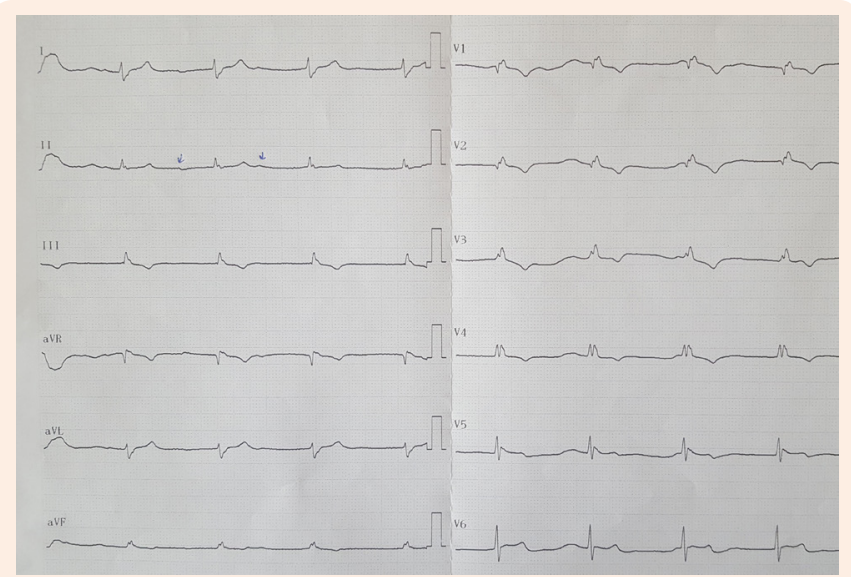

Figure 1

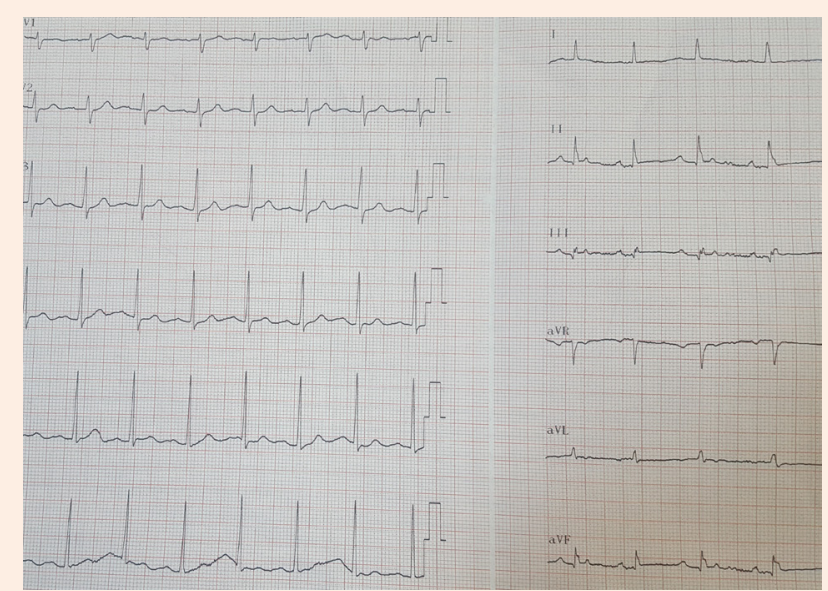

Figure 2

\section{Discussion}

Elderly patients also often develop AV node and His-Purkinje disease. It is common for patients to present to the emergency department with symptoms of fatigue, exercise intolerance, dizziness, near syncope, or syncope [4]. Our case was applied to emergency department similer symptoms and admitted to intensive care unit. Drugs such as digoxin or calcium channel blockers, can be caused hyperkalemia or hyperkalemia relaeted complete AV block. The patient's companion informed us that she didn't take any medication except for insuline.

Atrioventricular (AV) block is defined as a delay or interruption in the transmission of an impulse from the atria to the ventricles due to an anatomical or functional impairment in the conduction system. This disturbance of impulse transmission can be transient or permanent and may manifest as conduction delay in the AV node (first degree), intermittent failure of conduction from the atria to the ventricles (second degree), or complete (third degree) $\mathrm{AV}$ block [5]. Third-degree AV block is present when no $\mathrm{P}$ waves are conducted. The atrial rate is dissociated from the ventricular rate [4].

Severe hyperkalemia is an important cause of complete AV block. Although hyperkalemia is defined as a serum potassium concentration $>5 \mathrm{mmol} / \mathrm{L}$, moderate $(6-7 \mathrm{mmol} / \mathrm{L})$ and severe $(>7$ $\mathrm{mmol} / \mathrm{L}$ ) hyperkalemia are life-threatening and require immediate therapy. Hyperkalemia also may manifest as a conduction block at different levels, including bundle branch block or AV block; conduction defects in the specialized intraventricular conduction system are common in hyperkalemia and result in aberrant ECG patterns [6]. Electrocardiogram (ECG) findings in hyperkalemia progress from tall, "peaked" T waves and a shortened QT interval to a lengthening of PR interval and loss of $\mathrm{P}$ waves, and then to widening of the QRS complex, culminating in a "sine wave" morphology and death if not treated [7]. The correlation between the degree of ECG changes and the serum potassium level is poor; $\mathrm{AV}$ block is typically associated with a serum potassium level $>6,3$ $\mathrm{mmol} / \mathrm{L}$ [8]. Our patient's serum potassium level was $6,1 \mathrm{mmol} / \mathrm{L}$ and wide abnormal QRS complexes in all leads and complete AV block with a heart rate of 53 beats/min were observed on her ECG. It is aimed to place potassium into the cell in the treatment of the hyperkalemia, so IV, $\beta_{2}$ agonist agents, IV insuline treatments are admitted. Calsium gluconate protectes against to cardiac adverse effects and exchange resin is used for exchange sodium to potassium in gastrointestinal system. Hemodialysis is required if there are life-threatening hyperkalemia, chronic renal failure, rhabdomyolysis, untreatable or persistent hyperkalemia [9]. Calcium gluconate, inhaler $\beta_{2}$ agonist, IV insüline, fluid replacement administered but hemodialysis was not required.

Several case reports have published about hyperkalemia releated complete AV block in the literature. But these cases' serum potassium levels are greater than $6.3 \mathrm{mmol} / \mathrm{L}$ or serum potassium levels are lower than $6,3 \mathrm{mmol} / \mathrm{L}$ and renal failure accompany to hyperkalemia [2,7]. In spite of standard hyperkalemia treatment hemodialysis and pacemaker were required in the treatment of most patients. In presented case, despite serum potassium level was lower than $6,3 \mathrm{mmol} / \mathrm{L}$ and renal function parameter was 
normal, complete AV block occured. The other interesting sign in our case, she was treated without the temporaray pacemaker or hemodialysis. The elderly patients can be more sensitive in mild hyperkalemia than younger patients and clinical findings can occure earlier.

\section{Conclusion}

Hyperkalemia can be life-threatening, especially elderly patients and to be aware of cardiac complications. Examination findings, especially abnormal ECG findings and presence of bradyarrhythmia should be suspected hyperkalemia and the hyperkalemia treatment is started immediatly. Quick recognition and treatment is the main factor. Thereby patients should be treated without invasive procedures, such as hemodialysis or pacemaker.

\section{Conflict of interest}

None declared.

\section{Financial Disclosure}

The authors declared that this study received no financial support.

\section{References}

1. Dananberg J (1999) Electrolyte abnormalities affecting the heart. In: Schwartz GR (Ed.), Principles and practice of emergency medicine. ( ${ }^{\text {th }}$ edn), Williams \& Wilkins, Baltimore, USA, p. 425-427.
2. Rajanna N, Venkategowda PM, Murthy A, Katti P (2017) A Rare Case Of Reversible Heart Block In Patient With Acute Kidney Injury And Mild Hyperkalemia. International Journal Of Advances In Case Reports 4(1): 43-45.

3. Agarwal N, Singh A, Gaba R, Shukla R, Agarwal M, et al. (2015) Transient trifascicular block in severe hyperkalemia: A case report. J Assoc Physicians India 63(9): 74-75.

4. Byrnes TJ, Costantini 0 (2017) Tachyarrhythmias and Bradyarrhythmias Differential Diagnosis and Initial Management in the Primary Care Office. Med Clin N Am 101 495-506.

5. Sheyin 0, MgbemenaM, Magnus-Lawson 0, Salahudeen L, PierreLouis B, et al. (2014) High Grade Atrioventricular Block Presenting with Cardiac Arrest. American Journal of Cardiovascular Disease Research 2(2): 31-35.

6. Zohair Al Aseri (2012) Marked Symptomatic Bradycardia Associated with Profound Hyperkalemia. Emergency Medicine 2: 1.

7. Baratloo A, Haroutunian P, Rouhipour A, Safari S, Rahmati F (2015) Hyperkalemia-induced complete heart block. Journal of Emergency Practice and Trauma 1(1): 35-38.

8. Montague BT, Ouellette JR, Buller GK (2008) Retrospective review of the frequency of ECG changes in hyperkalemia. Clin J Am Soc Nephrol 3(2): 324-330.

9. Ayşegül Zümrütdal (2013) Sıvı Elektrolit Tedavisinde Temel Prensipler. Anadolu Kardiyol Derg 13: 171-177. 